\title{
O PARADIGMA DA INTERSETORIALIDADE NAS POLÍTICAS PÚBLICAS DE ESPORTE E LAZER
}

Recebido em: $26 / 11 / 2010$

Aceito em: 21/03/2011

\author{
Cláudia Regina Bonalume ${ }^{1}$ \\ Ministério do Esporte \\ Brasília - DF - Brasil
}

RESUMO: O presente artigo foi elaborado a partir da pesquisa Esporte e lazer na formulação de uma política pública intersetorial para a juventude: a experiência do PRONASCI, desenvolvida enquanto dissertação de mestrado da autora, na Universidade de Brasília, Programa de Pós-Graduação em Educação Física - 2010. O desafio que nos leva a construir reflexões acerca da temática da intersetorialidade parte do momento em que nos deparamos com o esporte e o lazer passando a comporem o rol das políticas sociais, ao, gradualmente, começarem a alcançar o status de direito social e, ao mesmo tempo, sendo desafiados a assumir um caráter intersetorial. Se conquistar o espaço de política pública, reconhecida como direito social, representa uma árdua tarefa, fazê-lo acontecer como proposta democrática, descentralizada, universal e intersetorial, demanda muito esforço e clareza por parte dos gestores e da população em geral.

PALAVRAS-CHAVE: Esportes. Atividades de Lazer. Políticas Públicas.

\section{THE PARADIGM OF INTERSECTIONALITY IN PUBLIC POLICY OF SPORT AND LEISURE}

ABSTRACT: This article was done from de research Sport and Leisure in the Construction of an intersectional Public Policy: the PRONASCI case developed as the author's dissertation, at University of Brasília, Graduate Program in Physical Education - 2010. The challenge that leads us to increase ideas about the subject of intersectionality, part of the time when we are faced with the sport and leisure through to compose the role of social policies, to gradually begin to attain the status of social right and, at the same time, being challenged to take an intersectional character. If conquer the space of public policy, recognized as a social right, is an arduous task, make it happen as a democratic, decentralized, universal and intersectional proposition,

\footnotetext{
${ }^{1}$ Mestre em Educação Física pela UnB. Diretora do Departamento de Políticas Sociais do Ministério do Esporte. Foi Chefe de Gabinete da Secretaria Nacional de Desenvolvimento de Esporte e de Lazer, do mesmo Ministério, entre 2006 e 2008 e Secretária Municipal de Esporte e Lazer de Caxias do Sul-RS entre 2000 a 2004.
} 
demand much effort and clarity on the part of administrators and the population in general.

KEYWORDS: Sport s. Leisure Activities. Public Policies.

\section{Esporte, lazer e políticas intersetoriais}

Assumindo o desafio de refletir sobre as políticas públicas intersetoriais, que envolvem o esporte e o lazer, partimos da constatação de que, nesse momento histórico de rápidas transformações e novas tecnologias, os direitos sociais vêm sendo cada vez mais demandados e proclamados - neles incluídos os direitos ao esporte e ao lazer. O dever do provimento a esses direitos articula-se, por sua vez, a outros aspectos, colocando-os como um setor de ação transversal que pode ser tanto enfatizado como processo quanto produto cultural de construção, vivência e definição de valores, diversidades, identidades, conhecimentos e competências. Também pode ser enfatizado como meio de formação dos atores para entender e participar do mundo onde vivem, conscientes da importância do esporte e do lazer, benefícios e riscos neles contidos. Leila Pinto (2004) acredita tratar-se de um processo educativo coletivo, que se inicia no nascimento e continua ao longo da vida.

No campo acadêmico, pensar o esporte e o lazer como direitos vem ganhando cada vez mais ênfase. O tema só passou a ser investigado pelas ciências sociais em meados do século XX, durante o processo de industrialização e urbanização, com o foco no tempo livre, considerado naquela época como sobra do tempo de trabalho. Depois avançou no campo das políticas públicas e do direito social, com os limites que fazem parte de todo processo histórico.

Já a intersetorialidade, embora seja tema e objeto de experiências e estudos significativos no País, que permitem o reconhecimento de sua importância e viabilidade nas políticas sociais, enfrenta muitas limitações no tocante a sua implantação prática, 
especialmente nos casos que envolvem políticas públicas de esporte e lazer, ainda parece enfrentar muitas limitações. Uma breve análise dos artigos publicados ao longo dos últimos $15 \operatorname{anos}^{2}$ indica pouca densidade de informações acerca do tema, ao mesmo tempo em que é crescente a busca pela concretização de ações intersetoriais envolvendo o esporte e o lazer nas políticas públicas brasileiras.

No geral, as experiências históricas que, na maioria das vezes, constituíram as políticas públicas de esporte e lazer no Brasil, caracterizaram-se por serem seletivas, fragmentadas, excludentes, setorizadas e, especialmente, desenvolvidas em forma de assistência e benesse. O poder público, historicamente, ficou mais como tutor dessas ações, por meio de isenções (clubes), doação de materiais, campanhas pela prática de atividade física, incentivos fiscais e repasses de recursos para a iniciativa privada e realizador de eventos esportivos e de lazer. "[...] em vez de direitos, favores e assistência" (MELO, 2005, p. 97). Poucas parecem ter sido as iniciativas do poder público no sentido de desenvolver, em sua totalidade, programas, projetos e ações, cujo objetivo central fosse garantir o acesso ao esporte e ao lazer, pautados como direitos sociais e focados no desenvolvimento humano.

Nos últimos tempos tem sido muito comum ouvirmos e/ou lermos que o esporte pode ser um grande diferencial na vida das pessoas; que o esporte e o lazer são imprescindíveis para a saúde, para a educação, para a formação de hábitos e valores, para tirar as crianças e jovens das ruas e afastá-los das drogas. A mídia e o mercado têm se encarregado de reforçar diariamente esses aspectos. Já é possível perceber o reflexo dessa maneira de pensar na vida das pessoas e no campo das políticas sociais.

\footnotetext{
${ }^{2}$ Foram consultados: a Revista Brasileira de Ciências do Esporte (RBCE), o banco de teses da CAPES, e publicações que se referem ou analisam políticas públicas intersetoriais, como as de Marcellino (2008), Pinto (2008) e Spósito (2007).
} 
Chama atenção o grande potencial de relação do esporte e do lazer com outras áreas, o que vem colocando-os na pauta de programas estruturantes da educação, da saúde, do desenvolvimento agrário, da cultura, do desenvolvimento social, da segurança, do turismo, dos direitos humanos, entre outros, que procuram atuar diretamente no enfrentamento de problemas ou questões sociais complexas. Sistematicamente, deparamo-nos com dúvidas quanto a esse tipo de intersetorialidade.

\section{Os desafios de uma ação intersetorial}

O desenvolvimento de ações integradas e intersetoriais implica ideias como parceria e solidariedade, que requerem o conhecimento do outro e das demandas que enfrentam juntos; a capacidade de gerir ações coletivas, de aglutinar aspirações, valores e estratégias, valorizando as diferenças e as relações constituídas, atentas aos problemas enfrentados e às alternativas encontradas.

O encontro com o outro, provocado pela relação intersetorial, pode ser a experiência mais extrema e cruel, bem como a mais enriquecedora, pois é ele que gerará a heterogeneidade, propondo o limite dos nossos desejos, interesses, necessidades e mesmo contrapondo-se ao nosso poder e nossa ambição de domínio. Ser plural exige perceber e aceitar o outro, muito além de ter apenas a ideia de sua existência. Faz parte da natureza humana buscar o estabelecimento de relações entre sujeitos, ações e saberes, para além da simples reunião, situá-los com precisão uns em relação aos outros. Como unificar interesses, ações e movimentos sem diminuir a diferenciação e as grandes margens de liberdade e individualidade conquistadas nas últimas décadas? (NOGUEIRA, 2003, p. 220)

Para início de reflexão nos colocamos em busca da totalidade do ser humanos, 
das políticas públicas e do conhecimento, cientes de que este todo é muito mais que uma junção de partes. Quando as racionalidades particulares não se articulam harmoniosamente umas às outras e o todo começa a mostrar-se problemático, tem-se um movimento de irracionalidade, desordem e caos. O princípio descarteano da separação divide as pessoas, as ações, as áreas do conhecimento e o objeto conhecido do sujeito conhecedor, levando ao princípio da especialização, que se revelou fecundo para diversos avanços, mas com diversas lacunas. Uma delas está, justamente, na falta da percepção de que muitas coisas nasceram nas fronteiras e zonas incertas entre um conhecimento e outro, uma ação e outra.

Além desse aspecto, as características das demandas sociais atuais implicam a percepção de que conhecer ou agir em partes não levará ao todo que, como já mencionamos, é mais do que a simples soma das partes e diretamente vinculado a elas. Trata-se da ideia dialógica, que aceita que duas instâncias não redutíveis uma à outra e contraditórias entre elas estejam ligadas intimamente (CHAUÍ, 1999, p. 36).

A metodologia intersetorial geralmente emerge quando determinada área do conhecimento ou da ação não dispõem de condições para, sozinha, atender determinada demanda, como se só alguns aspectos da vida e do conhecimento reclamassem uma visão e uma ação de totalização. Entre as diversas explicações para termos chegados à estrutura fragmentada de organização dos governos, das universidades, do comércio e da indústria, além de outros setores da sociedade, podemos arriscar uma síntese que parte do momento em que a sociedade passou a exigir e produzir mais conhecimento, o que levou ao surgimento de algumas áreas específicas, com o intuito de aprofundar esse saber - as especializações. Como a história também envolve a questão do poder e as organizações são espaços onde este se manifesta mais diretamente, o conhecimento 
passou a chegar até tais organizações, especialmente a partir da mudança no mundo da produção, marcada pela revolução industrial, e pela instituição e fortalecimento das universidades, com a especialização de profissionais de determinadas áreas. As demandas passaram a ser distribuída em diferentes espaços de atuação, transformados em campos de corporações profissionais, que se relacionam com seus públicos, singularizando-os de acordo com sua ação, sem considerar as outras necessidades ou demandas. A totalidade dos indivíduos, dos grupos, da vida, foi sendo ignorada. Nesse processo, cada vez mais, avançamos na produção e difusão do conhecimento, no acesso à formação e à informação, mas não superamos a lógica das disciplinas, assim como ampliamos as políticas públicas, mas não integramos as ações.

Vivemos em uma época em que se sente uma profunda necessidade de ações unificadoras e de métodos de superação de conhecimentos dispersos, capazes de reunir a prática e a teoria, o objeto e o sujeito, a realidade e o "valor" do homem, o conteúdo e a forma do pensamento, a ciência e a filosofia, todos os elementos da cultura.

No campo das políticas públicas a divisão do aparelho do estado em áreas fragmentadas de intervenção especializada precisa ser superada à luz das exigências da coordenação e gestão das ações, da matricialidade das políticas e da integração dos esforços no plano territorial. As demandas complexas, que vêm aumentando nesse período histórico, tendem a exigir a ampliação da proteção social e do desenvolvimento humano, para a obtenção de resultados mais eficazes, que demandam estratégias interdisciplinares, entre as políticas sociais, articulando as ações e respeitando as demandas regionais e de cada segmento.

Um dos aspectos para o qual chamamos a atenção é o uso indiscriminado do termo intersetorialidade. Uma leitura desatenta pode deixar passar desapercebidas essas 
singularidades. Ressaltamos uma análise feita por Mascarenhas (2008), a respeito de como vem se tornando comum "colar novas funções, qualidades ou novos atributos" às palavras, entre elas as que se referem ao direito ao esporte e ao lazer, provocando o que Bering $^{3}$ (apud MASCARENHAS, 2008) denomina "avalanche semântica". O autor ressalta que é preciso ter atenção com esse aspecto tendo sempre presente que os efeitos dos objetivos de um discurso devem ser sempre considerados no seu contexto para evitar que o poder mitificador do discurso forje uma "pseudo-coesão, um consenso, que acaba contribuindo com a legitimação das políticas sociais em curso" (MASCARENHAS, 2008).

Mencionamos isso para lembrar que a discussão sobre a intersetorialidade voltou a ganhar ênfase no século XX, mais especificamente no final dos anos 70, quando as sociedades capitalistas sofreram mais uma das crises do sistema, após os anos de walfare state. A opção de enfrentamento a essa crise se deu pela via do ideário neoliberal que vê na articulação entre setores uma das formas de enfrentar os problemas complexos, tendo como foco a possibilidade de redução dos custos operacionais, já que o bom estado deveria ser leve, ágil, reduzido, baseado na racionalidade técnica e vazio de ideais e interesses (MOTA, 2006). Assim, nessa perspectiva, que é muito mais restrita da que estamos defendendo aqui, a intersetorialidade é tratada como forma de otimização de recursos, via redução de custos.

Esses projetos neoliberais defendem a descentralização e a intersetorialidade como vias de otimização de recursos, particularização dos problemas sociais e redução de custos. Em alguns casos, o descentralizar, que deveria estar focado no democratizar, tem como meta real neutralizar o excesso de Estado, ou seja, descentralizando

\footnotetext{
3 BEHRING, Elaine Rossetti. Brasil em contra-reforma: desestruturação do Estado e perda de direitos. São Paulo: Cortez, 2003.
} 
atribuições e atividades, o Estado teria mais fôlego para se concentrar no fundamental, reduzir seus custos operacionais, diminuir de tamanho e ganhar mais leveza e agilidade (NOGUEIRA, 1997).

Tendo deixado claro que este não é o perfil de intersetorialidade no qual acreditamos, nos deparamos com um aparato governamental todo fatiado por conhecimentos, por saberes, por corporações, nos quais as pessoas, as famílias e/ou os grupos não são vistos como totalidades. Além disso, encontramos outros agravantes para a segmentação, tais como: a herança da hierarquia verticalizada, piramidal, na qual as decisões são tomadas apenas no topo, não na base, próximo à população; e o loteamento político-partidário e de grupos de interesses, do aparato governamental. Dessa forma, temos diversas fatias isoladas, cada qual preocupada com um aspecto da vida social, ainda submetidas ao loteamento político-partidário. Não estamos aqui fazendo a discussão acerca do mérito da divisão de espaços entre os partidos políticos que compõem a base de um governo democrático e sim tentando identificar as causas da fragmentação, a qual vimos tentando enfrentar. Considerando os aspectos mencionados a estrutura governamental, que deveria ser cooperativa, com vistas a melhorar a qualidade de vida das pessoas, torna-se competitiva. O ideal passa a ser prover cada uma das partes, com seus programas, projetos e ações, avaliar os produtos e não os resultados e a diferença que isso faz. Inojosa (2001, p. 104) ressalta que esse tipo de atuação não consegue superar as dificuldades da sociedade nem promover o efetivo desenvolvimento social.

Serrate (2007, p. 02), ao se referir à necessidade da intersetorialidade nas políticas públicas de saúde, afirma que sistemas complexos como o da saúde, com muitos elementos envolvidos, relações, propriedades, hierarquias e fronteiras, têm 
muitas maneiras de combinar-se e recombinar-se e que ficam submetidos a uma dinâmica muito elaborada, na qual categorias como causalidade, casualidade e possibilidade têm uma presença significativa. Os atores e as ações transcendem as fronteiras de um setor específico e isso exige uma resposta organizada, sem a qual o resultado é pouco significativo. "Cada uno por si solo no puede lograr el producto deseado y mucho menos si esas interrelaciones no tienen un mínimo de armonía y coherencia” (SERRATE, 2007, p. 02).

Grau (1998) sintetiza bem esses aspectos afirmando que a ênfase deixa de centralizar-se no interesse de uma ou outra parte e foca-se nas interações e nas relações de reciprocidade, ou seja, a promoção de ações intersetoriais é baseada na interrelação de necessidades de várias áreas, sujeitos e grupos, considerando suas influências mútuas, via relações diversificadas, heterogêneas e complexas, variando de acordo com as especificidades de cada demanda.

A intersetorialidade pode se apresentar, então, como uma das possibilidades de articulação entre os saberes e as ações, com vistas a construir resultados sinérgicos em situações complexas, alterando o impacto das políticas, tornando-as mais efetivas e ampliando sua capacidade de colaborar com a redução das desigualdades e com o bemestar social. Além disso, pode contribuir com a construção de uma nova ação, que rompa as fronteiras das políticas isoladas. Para que isso se viabilize integrar, considerando apenas a dimensão técnica não seria suficiente, faz-se necessário uma atitude e uma postura intersetorial, enquanto um princípio que orienta a ação, com um aparato governamental, com base no território e na população. Trata-se da articulação entre as políticas públicas por meio do desenvolvimento de ações conjuntas, destinadas ao alcance dos objetivos propostos. 
Uma proposta intersetorial precisa ter a capacidade de articular os vários campos sociais de um território no trato das demandas a serem atendidas na sua globalidade. Esse desafio implica a compreensão das necessidades sócio-culturais dos envolvidos nas ações políticas (familiares, escolares, de trabalho, esporte, lazer, cultura, etc) e de como cada ação governamental pode atuar sobre elas. A integração das ações caracteriza-se pela definição de finalidades compartilhadas, estruturadas de forma interdependente e complementar. A interdependência, aqui, significa, como afirma Nogueira (1997), que nenhuma das partes controla o resultado, ele está além dos atores e das vontades, ou seja, ganha autonomia lógica própria.

\section{A construção políticas públicas intersetoriais}

Como vimos, há uma grande complexidade presente na definição e na operacionalização da intersetorialidade, uma vez que sua implementação requer a superação de um modelo há muito hegemônico, no qual cada setor operacionaliza suas políticas em si e para si, tornando-se o próprio objeto de sua existência. Cada um se desenvolve em razão de suas demandas e de suas próprias soluções, operando a reafirmação do setor (ANDRADE, 2006, p. 171). Romper com isso consiste em uma mudança de paradigma e, como sabemos, paradigmas não são simples de serem alterados. Práticas e saberes intersetoriais precisam se construir como um novo espaço, com base nas questões concretas e complexas que a realidade apresenta, contando com a contribuição das diversas áreas, que trazem à tona seus acúmulos de história e conhecimento, para contribuir com o enfrentamento da questão, em sua totalidade.

$$
\text { Encontramos em Moesch (2008) uma caracterização sintética da }
$$
intersetorialidade como articulação entre sujeitos de setores sociais diversos e detentores 
de saberes, poderes e vontades diferenciados, para enfrentar questões complexas. Ela objetiva superar a fragmentação dos conhecimentos e estruturas sociais e, com isso, produzir efeitos mais significativos nas políticas sociais. Complementamos com Serrate (2007, p. 02) quando este afirma que a intersetorialidade é uma intervenção coordenada de instituições representativas, de mais de um setor social, em ações destinadas, total ou parcialmente, a tratar de problemas vinculados à determinada área (no caso do autor, a saúde) como parte importante de uma resposta social organizada. Isso consiste, fundamentalmente, em converter a cooperação fortuita ou casual em ações que se orientem estrategicamente para os problemas identificados e priorizados, lideradas por um setor central e apoiadas por políticas nacionais e locais, devidamente organizadas.

Lázaro (2008) destaca três dimensões fundamentais para a intersetorialidade, que consideramos importante:

a. a primeira, a dimensão dos princípios: é preciso que se tenha princípios claros e comuns;

b. a segunda diz respeito à necessidade de instrumentos específicos - programas, diretrizes, etc., que decorrem dos princípios;

c. a terceira, uma compreensão de território. A intersetorialidade não se faz fora do território concreto, com sujeitos concretos, a partir de instrumentos acordados e princípios comuns.

Abreu (2009, p. 79) amplia a reflexão lembrando que falar em se transformar estruturas significa ter presente à necessidade de se considerar as diversas dimensões que compõem a intersetorialidade e as próprias estruturas. Exemplifica referindo-se a três delas que são centrais: a política que trata da necessidade de atuar sobre as relações sociais objetivando transformá-las; a teórica, que necessita da construção de saberes e 
conhecimentos que venham a embasar a ação; e a ideológica, entendida como a transformação dos sujeitos sociais envolvidos, na direção da construção de uma nova consciência a respeito dos direitos sociais.

Para Souza (2006) os principais focos analíticos da política pública estão na identificação do tipo de problema que a mesma busca enfrentar, na chegada desse problema no sistema político (politics) e à sociedade política (polity) e nas instituições e regras que irão modelar a decisão e a implementação da política pública. Considerando que, entre o reconhecimento de um problema e a possibilidade de intervenção pública há uma permanente interação que envolve os diversos atores governamentais e não governamentais, constata-se que as etapas não são sucessivas e lineares.

A agenda governamental é formulada, segundo Kingdon (2003), por um conjunto de assuntos ou problemas no qual os gestores estão prestando atenção em um determinado momento. Para o autor o processo de formação de agenda é, simplesmente, o mecanismo pelo qual um assunto ou problema é relacionado entre aqueles que receberão atenção em determinado momento. Já a geração de alternativas é um processo que visa a construir soluções para os problemas da sociedade. A interpretação do problema influi diretamente na determinação do sistema de atores que será mobilizado na luta política. Essa decisão depende, no mínimo, de uma avaliação das várias opções disponíveis de ação, bem como das chances do tema se impor na arena política.

A intersetorialidade é um princípio que privilegia a integração matricial das políticas sociais, tanto na fase de planejamento quanto nas de execução, monitoramento e avaliação. Essa matricialidade representa o eixo coordenador e organizador dessas políticas, potencializando sua integração, com impacto positivo em seus efeitos. Isso implica planejamento e gestão compartilhada, ou seja, a construção de espaços de 
convergência de sujeitos que se completam à medida que se articulam esforços para atuar em prol de objetivos comuns.

Podemos afirmar, então, que uma das transformações desafiadoras de um programa intersetorial está na forma de coordenar atividades que envolvem muitas pessoas, segmentos e setores. Precisam ser consideradas as limitações de coordenação e de antecipação adaptativa, em matéria de ação coletiva. Isso requer uma gestão especial, fundamentada, segundo Molina (2002, p.17) nas seguintes características:

a. interação contínua com as outras atividades de formação das políticas;

b. abertura e interação permanente com os usuários e envolvidos;

c. flexibilidade e capacidade de resposta as frequentes mudanças no entorno;

d. claro entendimento das viabilidades técnicas, financeiras, políticas e institucionais, como base das ações a implementar;

e. bom conhecimento da organização assim como de sua relação com o entorno e uma grande capacidade coordenadora.

Serrate (2007, p. 5-9), ao pensar a área da saúde, define que os fatores que intervêm no desenvolvimento de ações com esse perfil podem ser classificados em três grupos: os determinantes, os condicionantes e os desencadeadores. Para ele, a falta de compreensão clara e precisa desses fatores dificulta o estabelecimento de formas de atuação com enfoques e métodos cientificamente fundamentados, nesse tipo de processo. Os fatores determinantes são os influentes para uma certa área ${ }^{4}$. Mapear esses fatores, os setores e as organizações que atuam sobre eles deve ser o ponto de partida de qualquer ação que vise ao desenvolvimento de uma proposta intersetorial.

\footnotetext{
${ }^{4}$ Por exemplo, no caso da saúde, Serrate (2007, p.7) cita a educação sanitária deficiente da população, os fatores de contaminação do meio ambiente, a delinquência e violência nas localidades, a falta de alimentação balanceada, o sexo inseguro, a má qualidade dos serviços de saúde, a pouca prática de atividades físicas, entre outras.
} 
Os fatores condicionantes são os considerados necessários para que a intersetorialidade aconteça. Serrate $(2007$, p. 8) indica:

a. vontade: base do condicionamento, disposição plena dos responsáveis pela gestão em assumir o enfoque tecnológico da intersetorialidade como princípio de atuação;

b. papel do Estado e do governo: as possibilidades de ações concretas dos estados e governos deverão contemplar os fatores políticos, econômicos e sociais, previstos de acordo com o enfoque tecnológico da intersetorialidade;

c. reformas adequadas na área: as reformas como mudanças, transformações em função da ação a ser desenvolvida devem conter, entre seus objetivos, o partilhar responsabilidades entre instituições, indivíduos e comunidade, assim como alcançar equilíbrio e complementação de esforços;

d. fortalecimento dos ministérios e secretarias: é importante considerar a necessidade de fortalecimento do perfil de gerência na área, em um contexto caracterizado pelas novas relações entre o governo e a sociedade civil, com a necessária previsão de recursos;

e. funções essenciais: após mapearem as demandas de determinada área, é preciso definir quais as funções essenciais que ficarão sob responsabilidade maior da coordenação e quais delas demandam ação intersetorial;

f. descentralização: entendida como o processo de passar aos níveis locais de gestão a autoridade, responsabilidade e recursos, o que é essencial para se obter uma ação com perfil intersetorial. Spósito (2007, p.24) lembra que a realização local de ações definidas em âmbito federal sofre filtros em seus mais diversos níveis, que vão desde a apropriação que os gestores municipais realizam das diretrizes e normas 
definidas, até a realização das ações em si. Sendo assim, a face local de uma política não espelha, necessariamente, as diretrizes, normatizações e formatos prescritos nas intenções da elaboração, ou se constitui em mera reprodução de práticas similares. O local pode ir de espaço de criação e inventividade social à versão piorada e simplificada da proposta inicial. Esse aspecto reforça a necessidade de planejamento integrado e gestão coletiva, inclusive entre as diversas instâncias envolvidas nas etapas de uma ação. Serrate (2007, p. 3) acredita que os resultados da intersetorialidade são maiores na medida em que se descentralizam os processos e os colocam, cada vez mais, no âmbito local e comunitário, onde os setores contem com poder e liberdade de ação suficientes para, coletivamente, enfrentar os problemas, cujas soluções permitam alcançar seus propósitos. Essa aproximação com o nível local possibilita que a população, na condição de sujeito e objeto, seja parte do enfrentamento dos problemas;

g. recursos humanos motivados: a existência de pessoal, no setor central e dos demais parceiros, motivado para o trabalho participativo, para a compreensão mútua do caráter social da ação, é imprescindível. Prepará-los para a intersetorialidade é um passo posterior, porém, sem essa motivação prévia, a formação não fará milagres;

h. inversão: agir intersetorialmente implica uma inversão tecnológica para além da estrutura físico-financeira. A produção e socialização de conhecimentos diversos gerados na área é condicionadora: pelas expectativas reais que origina ao promover novas ações similares; pela motivação dos atores com o alcançado; pelo fortalecimento dos recursos humanos envolvidos, que amplia sua capacidade de atuação, por meio de seu poder de participação;

i. sociedade organizada: os principais responsáveis pela intersetorialidade são aqueles que nela participam, não só como objeto, mas também como sujeitos de direção 
do processo, ou seja, a sociedade. A intersetorialidade requer vontade e até espontaneidade, mas precisa ser conduzida, sistematicamente, em um processo no qual cada um dos envolvidos tenha clareza dos objetivos, funções e ações que lhe compete desenvolver

A respeito dos fatores desencadeantes da intersetorialidade, o autor destaca que a resposta social organizada requer o domínio de enfoques, técnicas, habilidades e tecnologias tipicamente gerenciais, necessários para qualquer ação. No caso de ações intersetoriais, há uma preponderância das que têm a ver com as relações interpessoais: o trabalho em equipe, a criatividade, o consenso e a orientação social do objetivo comum. Do ponto de vista gerencial, os fatores desencadeantes da intersetorialidade são reunidos pelo autor em cinco grupos: o enfoque, as técnicas de trabalho em equipe, as habilidades e capacidade gerencial, as tecnologias gerenciais e a produção social na área.

\section{O esporte e o lazer na relação com outras políticas sociais}

O esporte e o lazer, no campo das políticas públicas, encontram a intersetorialidade como instrumento, na construção de ações de democratização, com possibilidade de reversão de processos históricos vividos no Brasil. Com a redemocratização do País, iniciada nos anos 80, algumas ações de caráter intersetorial desenvolvidas nos anos 90 conseguiram avançar, apesar do processo de desresponsabilização do Estado $^{5}$, no século XX e início do século XXI.

Mais recentemente o tema passou a integrar a pauta de discussões e decisões políticas no País, como, por exemplo, as três Conferências Nacionais de Esporte (2005, 2007 e 2010) que se revelaram como momentos privilegiados de avaliação da política e

\footnotetext{
${ }^{5}$ Como exemplos, podemos citar o processo de orçamento participativo, o desenvolvimento de escolas organizadas por ciclos de formação em muitos municípios brasileiros, bem como algumas políticas integradas na área da saúde.
} 
construção de agenda participativa, contribuindo para a definição das diretrizes e princípios, em forma de resoluções, a serem implementadas pelo poder executivo e pela sociedade civil.

As resoluções da I Conferência, apesar de abordarem a temática da intersetorialidade, ainda o fazem no sentido de se utilizar outras áreas para objetivos pontuais no campo do esporte e do lazer e não para compor uma política pública ampla, que dê conta do ser humano e da sociedade, integralmente.

Na mesma lógica, no preâmbulo do texto da Política Nacional do Esporte, criada a partir da I Conferência, ao tratar das manifestações esportivas previstas na Lei 9.615/98 (Lei Pelé): “Desporto Educacional, Desporto de Participação e Desporto de Rendimento", o texto faz referência a uma ação articulada com a Política Nacional de Educação, no caso do desporto educacional e à Política Nacional de Promoção da Saúde, no desporto de participação. A intersetorialidade aparece de forma expressa apenas uma vez no documento, no campo das diretrizes, repetido no item 9, "Das ações estratégicas", referindo-se especificamente à parceria com a saúde: "4. Promoção da saúde: Os programas de esporte devem servir como ferramenta eficaz para a promoção e prevenção da saúde, especialmente, sendo integrados em ações interdisciplinares de políticas públicas de saúde coletiva.”

A primeira proposta aprovada pela II Conferência (2007, p. 19), prevê a valorização da intersetorialidade:

O Sistema Nacional de Esporte e Lazer, tendo por base o regime de colaboração entre União, estados e municípios, com ênfase na municipalização, consolidando o esporte e o lazer como direitos sociais e guiando-se pelos princípios da democratização e inclusão social, articula, integra, promove e estabelece relações éticas de parcerias entre as entidades da sociedade civil, instituições públicas e privadas, em torno do esporte educacional, de participação e de rendimento, valorizando a acessibilidade, a descentralização, a intersetorialidade e a multidisciplinaridade das ações esportivas e de lazer. (Eixo I, Resolução 1, grifo nosso) 
No Eixo 3, "Gestão e controle social", encontramos os primeiros indicativos de um olhar menos utilitarista e mais compensador para a intersetorialidade:

1 - O Sistema Nacional de Esporte e Lazer tem por princípio a gestão democrática da esfera pública, objetivando o exercício pleno da cidadania, por meio da participação e da inclusão social, valorizando:

f) estabelecimento de parcerias técnicas e financeiras, convênios, consórcios e cooperações entre as três esferas governamentais, com a iniciativa privada e com o terceiro setor, a fim de viabilizar ações que estimulem e promovam o esporte e o lazer. Tais parcerias, convênios e cooperações deverão apontar para políticas intersetoriais, integrando o trabalho de equipes multidisciplinares e interdisciplinares, com as áreas da educação, saúde, cultura, turismo, meio ambiente, assistência social, entre outras [...] ““..

i) o caráter multiprofissional, multidisciplinar e interdisciplinar do esporte $\mathrm{e}$ do lazer

5 - as Secretarias - e/ou outros órgãos vinculados ao campo do esporte e do lazer - implantadas, nas três esferas de governo, quanto à gestão, deverão:

d) garantir a interface setorial e transversal com outras áreas afins (saúde, educação, meio ambiente, turismo, cultura, segurança, entre outras, grifo nosso).

Já nas resoluções da III Conferência encontramos diversas menções a intersetorialidade, o que comprova o avanço da temática na área. Na Linha Estratégica 2 - Formação e Valorização Profissional, Ação 5, porém com foco na formação continuada em educação física, esporte e lazer. Na Linha Estratégica 3, Esporte, Lazer e Educação a ação 2 prevê "ampliação e qualificação das ações intersetoriais dos Programas do Governo Federal”. Além destes a Linha Estratégica 4, Esporte, Saúde e Qualidade de Vida, indica diversas ações intersetoriais para a temática.

Como vimos pelas situações mencionadas e por outras que certamente cada um de nós vêm tendo contato, vincular o esporte e o lazer a áreas diversas tem estado muito em voga. Acreditamos ser essa uma boa possibilidade de afirmação do campo como política pública que, ao dialogar com as demais áreas, pode vir a contribuir significativamente com a construção de uma sociedade mais igualitária. Como ponto de partida, no intuito de se evitar julgamentos simplistas e ingênuos, precisamos considerar que o esporte e o lazer não são, em si, bons ou maus. 
Esses apontamentos não objetivam, de maneira alguma, duvidar da necessidade da intersetorialidade das políticas públicas e do envolvimento do esporte e do lazer nessa relação. Muito pelo contrário, acreditamos na impossibilidade de uma real eficiência e efetividade dessas políticas, isoladamente. Podemos instigar a reflexão perguntando: como pensar em uma ação de esporte e lazer junto a moradores das áreas mais empobrecidas dos grandes centros urbanos, as favelas, sem considerar a necessidade de relacioná-las, por exemplo, com a questão da moradia ${ }^{6}$, visto que nessas áreas não existem espaços públicos de qualidade para a convivência, o esporte e o lazer? Como pensar em políticas públicas de esporte e lazer nos grandes centros urbanos sem considerar a questão do trânsito e do transporte que, atualmente, tomam um tempo cada vez maior da população, geralmente o tempo que ela teria para o lazer?

Temos a convicção de que pensar em políticas públicas de esporte e de lazer, assim como em políticas públicas para as diversas políticas sociais, depende de uma relação estreita e planejada entre diversas áreas de atuação. Nossa questão é: qual a relação que pode contribuir com tal intuito e como construí-la?

Cumpre explicitar as relações que não contribuem com o desafio a ser enfrentado pelo esporte e pelo lazer ao compor políticas de caráter intersetorial, mas que, seguidamente, têm estado presentes. Como primeira delas citamos o caráter utilitarista e redentor com o qual o esporte e o lazer são tratados. Neste sentido chamamos a atenção para dois aspectos essenciais: o primeiro, que não é o esporte e/ou o lazer, por si só, que podem contribuir para a solução de problemas como a violência e o sedentarismo da população, e sim, o conjunto dos direitos sociais garantidos universalmente; e o segundo, que a responsabilidade por essa garantia precisa ser

\footnotetext{
${ }^{6}$ Considerando que a Organização Mundial da Saúde recomenda, para cada pessoa, $12 \mathrm{~m}^{2}$ por habitação e a média, nessas áreas, é de $40 \mathrm{~m}^{2}$ por residência, onde vivem, geralmente, mais de cinco pessoas.
} 
assumida pelo Estado. Suassuna (2007) destaca a importância de se fortalecer o debate no sentido de redimensionar o papel do lazer e percebê-lo numa perspectiva de emancipação humana, retirando-lhe a alta carga funcional, ligada, inclusive no texto constitucional, à seguridade social. Como busca de superação dessa realidade, nos deparamos com o desafio de desenvolver políticas públicas de esporte e lazer com qualidade social, acessíveis a todos, como possibilidade de contraponto à lógica social de desigualdade, exclusão e desrespeito às diversidades, que vemos atualmente.

$\mathrm{Na}$ mesma linha do caráter utilitarista encontramos muitas justificativas para o desenvolvimento de políticas públicas de esporte e lazer, especialmente as voltadas a crianças e jovens pertencentes às classes sociais mais empobrecidas, com forte presença do que se chama de "ideologia salvacionista". Melo (2005, p. 16) afirma que se trata da ideologia que não vê o esporte e o lazer como direitos sociais, mas acredita na oferta de atividades esportivas e de lazer como antídotos contra a entrada de crianças e jovens no mundo da droga e do crime.

Há, também, uma tendência de se enfocar o acesso ao esporte e ao lazer, como desenvolvimento de possibilidades de profissionalização, vinculadas aos exemplos de sucesso e ao reconhecimento do esforço individual, assim como ferramenta de controle e disciplinamento, ao permitir a canalização da energia e o domínio sobre os impulsos violentos. Esses enfoques tendem a direcionar os objetivos das políticas públicas de esporte e lazer para afastar crianças jovens das ruas, das drogas e da violência, atribuindo-lhes o já mencionado caráter civilizador, salvacionista ou redentor.

Se considerarmos que a grande preocupação dos gestores de esporte e lazer, geralmente, parece estar em afirmar o poder que o esporte tem como ferramenta para outras áreas, é difícil imaginar que o sentido disso estaria no desenvolvimento de 
políticas intersetoriais de fato. Assim, o esporte e o lazer na relação com outras políticas sociais vem sendo cada vez mais proclamados e valorizados, porém é preciso sempre ter presente os limites e possibilidades. Fica o reforço à necessidade de se garantir um olhar crítico e contextualizado, com vistas a perceber e buscar formas de superação destes limites e investir na potencialização das possibilidades reais. O risco é o de aceitar qualquer ação louvável ou espirituosa, desde que bem desenvolvida, em nome do esporte e do lazer, mas que, no fundo, pode estar repleta de outras intenções. É preciso buscar um esporte e um lazer pensados de maneira integrada, pedagógica e sistemática, com profissionais preparados e conscientes de como pensar sociedades mais justas e democráticas.

O trabalho para o alcance desta expectativa deve buscar a garantia de que o esporte e o lazer passem a ser reconhecidos e tratados da maneira indicada por Gutierrez (1997), como princípios muito caros à construção da subjetividade no mundo contemporâneo, como a liberdade, o desapego e o hedonismo, reforçada por Pinto (2004) ao destacar que estas mudanças precisam garantir o sentido principal de tempo de experiência lúdica com diversos significados entre os quais o de pertencimento, encontro e repetição criativa da prática cultural vivida. A autora lembra que no tempo social de lazer são concretizadas trocas diversas, nos diferentes espaços sociais, reveladoras de como os sujeitos produzem e consomem culturas, segundo suas identidades e modos de lidar com o tempo e o lugar. Estruturas que variam de acordo com as relações estabelecidas e condições vividas em cada grupo social, articuladas por diferentes lógicas de estruturação espaço-temporal das relações vividas.

É importante ter clareza do tipo de relação que se pretende construir em determinada política intersetorial, no sentido de facilitar a correta compreensão a 
respeito das interpretações presentes nestas relações e das intervenções que vêm sendo feitas. Isso demanda uma análise processual, passando pelos contextos político, social, econômico e cultural, uma vez que, como já mencionamos, as políticas sociais precisam ser analisadas enquanto construções históricas, que, apesar de apresentarem peculiaridades específicas dos contextos onde e quando acontecem, resultam das contradições evidenciadas na sociedade.

\section{Considerações finais}

Acreditamos que ações integradas certamente favorecem a compreensão do esporte e do lazer enquanto direitos sociais, como dimensões da cultura, com grande potencial de relação com diversas áreas de conhecimento e de ação, por estarem mais

próximas do conceito de totalidade. Para a efetivação dessas políticas é preciso considerar: o perfil multidisciplinar dos sujeitos envolvidos; a diversidade e pluralidade dos interesses culturais do lazer, entre eles o esporte; a crescente preocupação e valorização com a utilização do tempo livre, para além da simples ocupação; a capacidade de mobilização e organização das pessoas; o entendimento atual de que intersetorialidade deixa de ser uma proposta de gestão e passa a ser um requisito essencial na formulação de políticas públicas.

Podemos afirmar que, se enfrentadas as questões mais complexas de definição de ações e adoção de medidas estruturais, técnicas, financeiras e legais adequadas, ainda assim o sucesso de uma ação integrada depende de:

a. critérios de acesso planejados coletivamente, integrando e intersetorializando ações; 
b. existência de uma porta única de entrada das demandas, evitando-se privilégios;

C. socialização das informações importantes para a ação realizada, entre todos os envolvidos,

d. estrutura que permita a percepção, por todos, dos problemas e das oportunidades vividos;

e. produção de uma estrutura de sentidos e propósitos que dão identidade e valor às ações realizadas;

f. novo olhar, com consciência ética dos diversos envolvidos;

g. clareza e coerência dos fins e meios da implantação da política, de seus pressupostos, diretrizes e formas de gestão das ações realizadas.

h. processos contínuos de avaliação.

Ou seja, ao assumir o desafio da intersetorialidade, é fácil imaginarmos a resposta necessária, mas muito difícil construí-la, já que o processo de construção de um Estado fragmentado teve um efeito perverso, indesejado e extremamente persistente. Mais do que trazer a proposta de ação intersetorial, é preciso desenvolver um amplo processo de transformação política, ideológica e da prática em políticas públicas. Essa transformação só poderá acontecer quando o Estado, no seu sentido amplo, tiver construído elementos de superação da hegemonia que coloca as partes, paralelas umas as outras, como forma de ver e tratar o todo. Este desafio está muito além do alcance de ações intersetoriais pontuais, mas essas, por sua parte, estarão dando sua contribuição à construção da contra-hegemonia da totalidade se:

a) forem construídas com e a partir das demandas dos grupos, sujeitos e territórios envolvidos, atentas às necessidades e interesses destes; 
b) buscarem aproximar interesses ações e movimentos, considerando a diversificação;

c) tiverem presente que não se trata de construir o novo, desconsiderando a história e o processo que permitiu chegar até ele;

d) superarem o caráter utilitarista, presente em muitas propostas ditas intersetoriais, cujos objetivos centrais são a redução do papel do governo, a redução de custos e a potencialização de ações, o que não contribui com a transformação que estamos defendendo;

e) tiverem a busca da totalidade como princípio central, o que demanda, muito mais a dimensão técnica e de gestão, atitudes e posturas coerentes com esse princípio.

\section{REFERÊNCIAS}

ABREU, Cassiane C. A intersetorialidade no processo de construção da política de saúde brasileira. 2009. Dissertação (Mestrado) - Política Social, Universidade Federal do Espírito Santo, Vitória, 2009.

ANDRADE, Luiz O. M. A saúde e o dilema da intersetorialidade. São Paulo: Hucitec, 2006.

Brasil. Lei 9615. De 24 de março de 1998 (Lei Pelé) http://www.planalto.gov.br/ccivil_03/Leis/L9615consol.htm

I Conferência Nacional do Esporte. Documento final. Brasília, DF: Ministério do Esporte, 2005.

II Conferência Nacional do Esporte. Documento final. Brasília, DF: Ministério do Esporte, 2007.

III Conferência Nacional do Esporte. Documento final. Brasília, DF: Ministério do Esporte, 2010.

. Secretaria Especial dos Direitos Humanos, Observatório das Favelas. 
CHAUÍ, M. Uma ideologia perversa. Folha de São Paulo, São Paulo, 14, mar. 1999. Caderno Mais, p. 3.

GRAU, Núria Cunill. Repensando o público através da sociedade: novas formas de gestão pública e representação social. Rio de Janeiro: Revan/Brasília: ENAP, 1998.

GUTIERREZ, G. L. O lazer na atualidade: contribuição para uma reflexão metodológica. In: Encontro de História do Esporte, Lazer e Educação Física, 5, Ijuí. Anais. Ed. Unijuí, 1997.

INOJOSA, Rose Marie. Sinergia em políticas e serviços públicos: desenvolvimento social com intersetorialidade. Cadernos FUNDAP, São Paulo, n. 22, 2001, p. 102-110.

KINGDON, John W. Agendas, alternatives, and public policies. 2. ed. New York: Addison-Wesley Educational Publishers, 2003.

LÁZARO, André L. F. Lazer e intersetorialidade, in PINTO, et. al. (Org.) Brincar, jogar, viver: lazer e intersetorialidade com o PELC. Brasília: Gráfica e Editora América LTDA, 2008.

MARCELlinO, Nelson C. (Org.) Políticas públicas de lazer. Campinas: Editora Alínea, 2008.

MASCARENHAS, F. O Estado brasileiro e os direitos sociais: o lazer. SEMINÁRIO DE POLÍTICAS SOCIAIS DE EDUCAÇÃO FÍSICA, ESPORTE E LAZER I, 2008, São Caetano do Sul. Palestra, São Caetano do Sul. Universidade Municipal de São Caetano do Sul, 2008.

MELO, Marcelo de Paula. Esporte e juventude pobre: políticas públicas de lazer na Vila Olímpica da Maré. Campinas: Autores Associados, 2005.

MOESCH, Marutschka M. Lazer na intersetorialidade das políticas públicas: novos olhares. In: PINTO, et al. (Org.) Brincar, jogar, viver: lazer e intersetorialidade com o PELC. Brasília: Gráfica e Editora América LTDA, 2008.

MOLINA, Carlos Gerardo. Modelo de formación de políticas y programas sociales. Notas de clase. Washington, BID/INDES, 2002. Mimeo. 23 p.

MOTA, A. E. Seguridade social brasileira: desenvolvimento histórico e tendências recentes. In: TEIXEIRA, M. (Org.). Serviço social e saúde: formação e trabalho profissional. São Paulo: Cortez, 2006. cap. 2, p. 40-72.

NOGUEIRA, M. A. As três ideias de sociedade civil, o estado e a politização. In: COUTINHO, Carlos Nelson e TEIXEIRA, Andréa de Paula (Org.). Ler Gramsci, entender a realidade. ENCONTRO INTERNACIONAL DE ESTUDOS, II, 2003. Rio de Janeiro, Anais..., Rio de Janeiro, Civilização Brasileira, 2003. 289p.

NOGUEIRA, Marco Aurélio. A dimensão política da descentralização participativa. Revista São Paulo em Perspectiva, v. 11, n. 03, jul.-set./1997. 
PINTO, Leila M. S. de M. Sentidos e significados de tempo de lazer na atualidade: estudo com jovens belo-horizontinos. Tese (Doutorado) - Educação, UFMG Faculdade de Educação, Belo Horizonte, 2004.

PINTO, Leila M. S. et al. Brincar, jogar, viver: lazer e intersetorialidade com o PELC. Brasília: Ministério do Esporte, 2008.

SERRATE, P. C. Comprensión conceptual y factores que intervienen em el desarrollo de la intersectorialidad. Revista Cubana de Salud Pública, La Havana, v. 33, n. 2, 2007.

SOUZA, Celina. Políticas Públicas: uma revisão de literatura. Revista Sociologias, n. 16, Porto Alegre, julho/dezembro 2006.

SPÓSITO, M. (Coord.). Espaços públicos e tempos juvenis: um estudo de ações do poder público em cidades de regiões metropolitanas brasileiras. São Paulo: Global, 2007.

SUASSUNA, D. et al. O Ministério do Esporte e a definição de políticas para o esporte e lazer. In: SUASSUNA, D. e AZEVEDO, A. (Org.). Política e lazer: interfaces e perspectivas. Brasília: Thesaurus, 2007. p. 13 a 42.

\section{Endereço da Autora:}

Cláudia Regina Bonalume

SHN, Quadra 02, Bloco H, ap 1104

Brasília - DF - CEP 70702 - 905

Endereço Eletrônico: claudia.bonalume@esporte.gov.br 